\title{
The effect of passive mobilization associated with blood flow restriction and combined with electrical stimulation on cardiorespiratory safety, neuromuscular adaptations, physical function, and quality of life in comatose patients in an ICU: a randomized controlled clinical trial
}

Thaís Marina Pires de Campos Biazon ${ }^{1}$, Cleiton Augusto Libardi ${ }^{2}$, Jose Carlos Bonjorno Junior ${ }^{3,4}$, Flávia Rossi Caruso ${ }^{1}$, Tamara Rodrigues da Silva Destro ${ }^{1}$, Naiara Garcia Molina', Audrey Borghi-Silva ${ }^{1}$ and Renata Gonçalves Mendes ${ }^{*}$ (i)

\begin{abstract}
Background: Intensive care unit-acquired atrophy and weakness are associated with high mortality, a reduction in physical function, and quality of life. Passive mobilization (PM) and neuromuscular electrical stimulation were applied in comatose patients; however, evidence is inconclusive regarding atrophy and weakness prevention. Blood flow restriction (BFR) associated with PM (BFRp) or with electrical stimulation (BFRpE) was able to reduce atrophy and increase muscle mass in spinal cord-injured patients, respectively. Bulky venous return occurs after releasing BFR, which can cause unknown repercussions on the cardiovascular system. Hence, the aim of this study was to investigate the effect of BFRp and BFRpE on cardiovascular safety and applicability, neuromuscular adaptations, physical function, and quality of life in comatose patients in intensive care units (ICUs).

Methods: Thirty-nine patients will be assessed at baseline (T0-18 h of coma) and randomly assigned to the PM (control group), BFRp, or BFRpE groups. The training protocol will be applied in both legs alternately, twice a day with a 4-h interval until coma awake, death, or ICU discharge. Cardiovascular safety and applicability will be evaluated at the first training session (T1). At T0 and $12 \mathrm{~h}$ after the last session (T2), muscle thickness and quality will be assessed. Global muscle strength and physical function will be assessed $12 \mathrm{~h}$ after T2 and ICU and hospital discharge for those who wake up from coma. Six and 12 months after hospital discharge, physical function and quality of life will be re-assessed.
\end{abstract}

\footnotetext{
*Correspondence: renatamendes@ufscar.br

${ }^{1}$ Cardiopulmonary Physical Therapy Laboratory, Department of Physical

Therapy, Federal University of São Carlos, Rod. Washington Luiz, km 235 - SP

310, CEP 13565-905, São Carlos, Brazil

Full list of author information is available at the end of the article
}

(c) The Author(s). 2021 Open Access This article is licensed under a Creative Commons Attribution 4.0 International License, which permits use, sharing, adaptation, distribution and reproduction in any medium or format, as long as you give appropriate credit to the original author(s) and the source, provide a link to the Creative Commons licence, and indicate if changes were made. The images or other third party material in this article are included in the article's Creative Commons licence, unless indicated otherwise in a credit line to the material. If material is not included in the article's Creative Commons licence and your intended use is not permitted by statutory regulation or exceeds the permitted use, you will need to obtain permission directly from the copyright holder. To view a copy of this licence, visit http://creativecommons.org/licenses/by/4.0/ The Creative Commons Public Domain Dedication waiver (http://creativecommons.org/publicdomain/zero/1.0/) applies to the data made available in this article, unless otherwise stated in a credit line to the data. 
Discussion: In view of applicability, the data will be used to inform the design and sample size of a prospective trial to clarify the effect of BFRpE on preventing muscle atrophy and weakness and to exert the greatest beneficial effects on physical function and quality of life compared to BFRp in comatose patients in the ICU.

Trial registration: Universal Trial Number (UTN) Registry UTN U1111-1241-4344. Retrospectively registered on 2 October 2019. Brazilian Clinical Trials Registry (ReBec) RBR-2qpyxf. Retrospectively registered on 21 January 2020, http://ensaiosclinicos.gov.br/rg/RBR-2qpyxf/

Keywords: Blood flow restriction, Electrical stimulation, Cardiorespiratory safety, Intensive care unit-acquired atrophy, Intensive care unit-acquired weakness, Neuromuscular adaptations, Physical function, Quality of life, Critical care

\section{Background}

Intensive care unit (ICU) therapies that are used to stabilize severe illnesses, such as sedatives, invasive access, and mechanical ventilation are responsible for prolonged lengths of bed restriction and, consequently, for reducing mobility in ICU [1-6]. In turn, mobility restriction is associated with losses in muscle mass and strength $[4,7-13]$.

ICU-acquired atrophy begins within the first $48 \mathrm{~h}$ of severe disease [14-16] and increases during the first two weeks of intensive care [15-17]. Studies suggest that severely ill patients may lose from 25 to $40 \%$ of peripheral muscle strength in two or more days of invasive mechanical ventilation [18-20]. During the first week of intensive care, there is evidence of associations between atrophy and weakness with high mortality rates [21-24] and, interestingly, even after discharge from the ICU with reduced physical function [25], higher functional dependence [2628 ], and a reduction in quality of life [29-31].

Passive mobilization (PM) has been applied as a therapeutic strategy to reduce low mobility in patients unable to perform active exercises due to sedation [32] or non-induced comatose state [33], but without evidence of muscle atrophy and weakness prevention. Neuromuscular electrical stimulation $[7,8]$ is another strategy applied in critical care, involuntarily evoking muscle contractions through low-tension electric pulses [34]. Despite this, the efficacy of electrical stimulation still appears to be inconclusive, especially for severely ill patients [35, 36].

Barbalho et al. [37] investigated the use of blood flow restriction (BFR) associated with PM (BFRp) in comatose elderly patients in ICUs. This method consists of controlled mechanical compression to the muscle blood vessels through a pneumatic cuff [38], aiming to reduce arterial supply and muscle venous return and, consequently, stimulating muscle protein synthesis. In an intra-subject design study, both groups (PM and BFRp) presented muscle atrophy, although the application of BFR in one of the limbs efficiently reduced the loss of muscle mass. There were no adverse events, and the authors suggested BFRp as an effective strategy to reduce the magnitude of muscle mass loss.

Abe et al. [39] highlighted the intensity of exercise associated with BFR as an important aspect to optimize neuromuscular adaptations. Thus, Gorgey et al. [40] demonstrated a $17 \%$ increase in muscle mass after BFR combined with electrical stimulation in spinal cord-injured patients, compared to isolated electrical stimulation. Given the impossibility of performing active exercises, it seems also necessary to investigate the effects of $B F R$ associated with $P M$ and combined with electrical stimulation (BFRpE) in comatose patients to prevent muscle atrophy and weakness and possibly to optimize physical function and quality of life in ICU survivors.

Regarding BFR safety, after the release of betweensets BFR, rapid local muscular blood inflow and bulky venous return occur [41], which can lead to unknown repercussions in the cardiovascular system [42]. Consequently, these repercussions may reflect in critical changes in vital signs of severely ill patients and therefore in health recovery.

Hence, the present study aimed to investigate the effect of BFRp and BFRpE on cardiovascular safety and applicability, neuromuscular adaptations, physical function, and quality of life in ICU coma patients. We hypothesized that there will be no negative cardiovascular repercussions of BFRp, BFRpE, and BFRp will be able to reduce and BFRpE to prevent muscle atrophy and weakness, in addition to exerting more positive effects on physical function and on quality of life compared to BFRp.

\section{Methods}

\section{Primary objectives}

The primary objectives are to investigate the effect of BFRp and BFRpE on cardiovascular safety in comatose patients in the ICU and to investigate the applicability of such protocols as early motor intervention methods in intensive care. 


\section{Secondary objective}

The secondary objective is to investigate the effects of this intervention on neuromuscular adaptations, physical function, and quality of life of ICU coma-surviving patients.

\section{Study design}

This study describes a protocol for a pilot study of a double-blind, randomized controlled clinical trial of applicability and intervention, with transverse temporality and a three-arm factorial intervention design in accordance with the Standard Protocol Items: Recommendations for Interventional Trials (SPIRIT) guidelines. The SPIRIT verification list can be found in the Additional File 1 and is represented in Fig. 1. The flowchart for the clinical trial is shown in Fig. 2.

\section{Study setting}

The clinical trial will be carried out in the teaching and research ICU at the Irmandade da Santa Casa de Misericórdia de São Carlos, located in the city of São Carlos, São Paulo, Brazil. This ICU consists of 10 beds, and there is an average of 40 patients admitted monthly. Adult clinical and surgical patients with all types of diseases are treated in the ICU, and the average length of stay is 8 days.

\section{Sample size rationale}

A total of 30 participants were used for the sample size calculation of the clinical trial [43]. Therefore, a sample of 39 patients will enable $10 \%$ sample loss for each experimental group (PM/control, BFRp, and BFRpE). Based on a recruitment average of 24 patients per month, $20 \%$ of non-consent and $30 \%$ of non-previewed death or immediate discharge, we aimed to recruit 7.2 patients per month. The recruitment in a single ICU will allow the study to be completed in a minimal period of 6 months.

\section{Study population}

The inclusion, non-inclusion, and exclusion criteria are shown in Table 1. All the criteria will be reevaluated before each training session, according to the clinical specificity of the criteria (Table 1). All non-included patients will be re-evaluated after $18 \mathrm{~h}$ of coma, except for patients whose hospitalization is longer than $18 \mathrm{~h}$ prior to ICU admission. In conclusion, all patients will be assisted by the ICU physiotherapy team. Additionally, the number of PM sessions or any type of physical

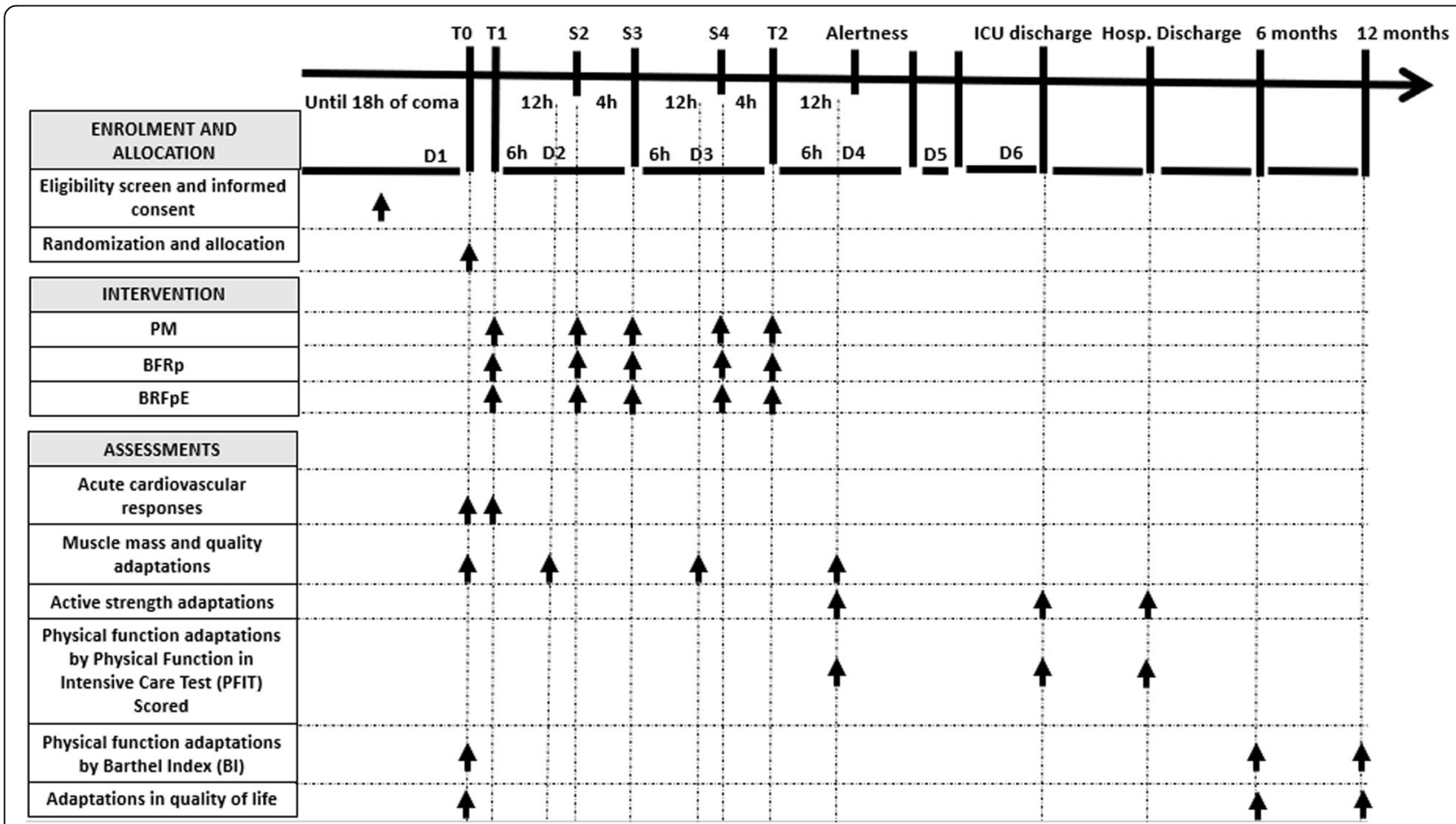

Fig. 1 Schedule of enrollment, interventions, and assessments of a patient with 6 days of ICU permanence. ICU, intensive care unit; Hosp., hospital; T0, baseline time point-initial evaluation; T1, time point 1—evaluation during the first training session; S2, session 2—second training session; S3, session 3-third training session; S4, session 4-fourth training session; T2, time point 2—last training session; D1, day 1; D2, day 2; D3, day 3; D4, day 4; D5, day 5; D6, day 6; PM, passive mobilization; BFRp, blood flow restriction associated with passive mobilization; BRFpE, blood flow restriction associated with passive mobilization and combined with neuromuscular electrical stimulation 


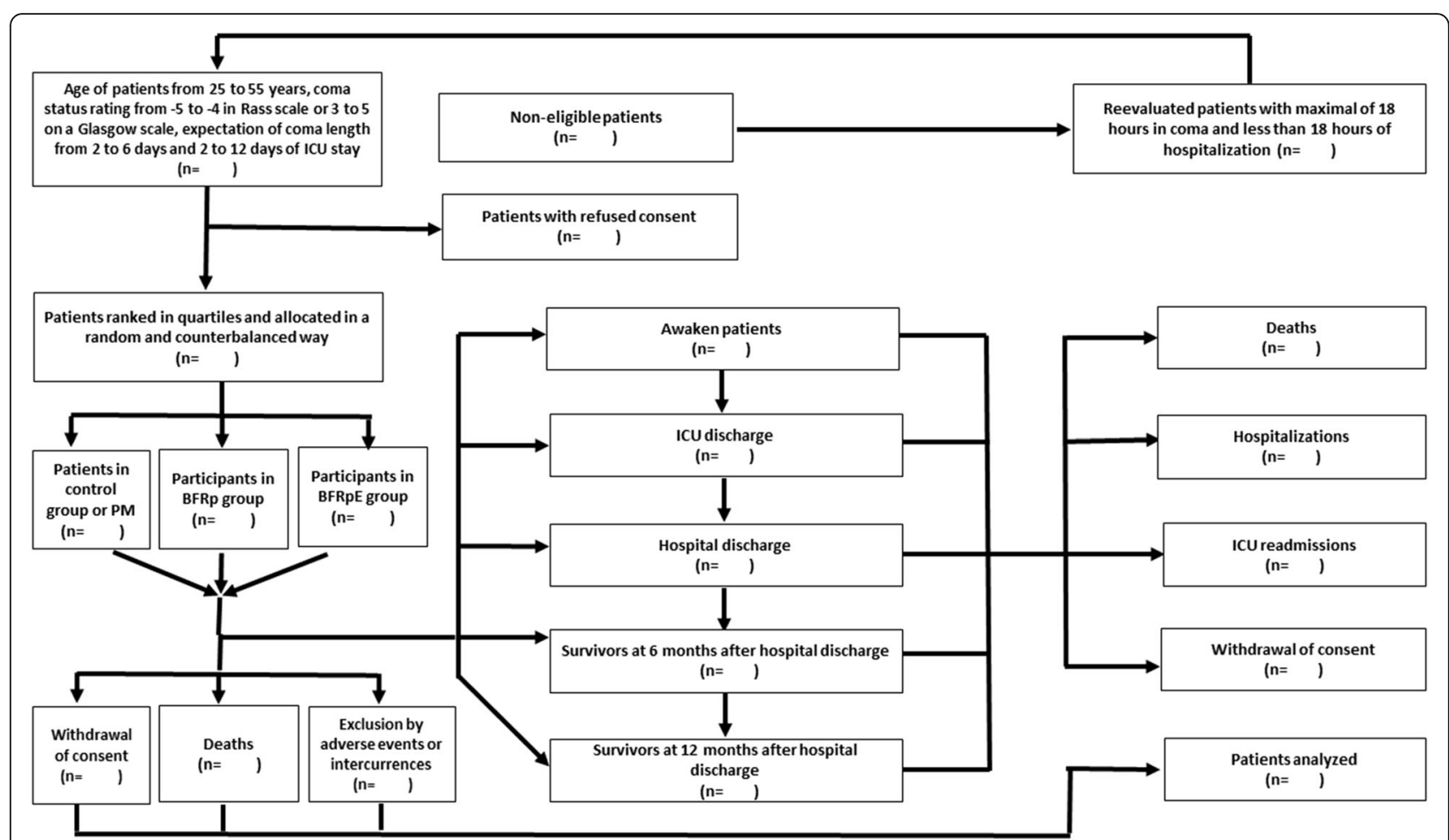

Fig. 2 Flowchart of the pilot clinical trial. ICU, intensive care unit; PM, passive mobilization; BFRp, passive mobilization associated with blood flow restriction; BFRpE, passive mobilization associated with blood flow restriction and combined to neuromuscular electrical stimulation

Table 1 Inclusion, non-inclusion, and exclusion criteria of the study population

\begin{tabular}{|c|c|c|}
\hline Inclusion criteria & Non-inclusion criteria & Exclusion criteria \\
\hline 1. Age of 25 to 55 years & $\begin{array}{l}\text { 1. Persistent arrhythmia } \\
\text { with atrial fibrillation }\end{array}$ & 1. Obese $\left(\mathrm{BMI}>30 \mathrm{~kg} / \mathrm{m}^{2}\right)$ \\
\hline $\begin{array}{l}\text { 2. Scores }-5 \text { or }-4 \text { according to the Richmond } \\
\text { Agitation-Sedation Scale (RASS) or } 3 \text { to } 5 \text { in the Glas- } \\
\text { gow Comatose Scale }\end{array}$ & $\begin{array}{l}\text { 2. Pre-existing atrioven- } \\
\text { tricular block or ventricular } \\
\text { tachycardia }\end{array}$ & 2. More than one thromboembolism risk factor \\
\hline $\begin{array}{l}\text { 3. Maximal } 18 \mathrm{~h} \text { of coma in ICU admission or during } \\
\text { critical care hospitalization }\end{array}$ & $\begin{array}{l}\text { 3. Recent acute } \\
\text { myocardium infarction }\end{array}$ & 3. Previous venous thrombosis and/or pulmonary embolism \\
\hline 4. Prediction of coma length between 2 and 6 days & $\begin{array}{l}\text { 4. Provisional or definitive } \\
\text { pacemaker }\end{array}$ & $\begin{array}{l}\text { 4. Peripheral arterial vascular disease history or suspicion of lower } \\
\text { limb arterial insufficiency }\end{array}$ \\
\hline 5. Prediction of 2 to 12 days of ICU permanence & $\begin{array}{l}\text { 5. Signals of intracranial } \\
\text { hypertension }\end{array}$ & $\begin{array}{l}\text { 5. Severe cardiovascular instability and/or use of vasoactive drugs } \\
\text { in infusion } \geq 0.5 \mathrm{mcg} / \mathrm{kg} / \mathrm{min}\end{array}$ \\
\hline \multirow[t]{6}{*}{$\begin{array}{l}\text { 6. Daily protein consumption standardized for the } \\
\text { ICU medical and nutrition teams }\end{array}$} & $\begin{array}{l}\text { 6. Neoplasia in } \\
\text { chemotherapy treatment }\end{array}$ & $\begin{array}{l}\text { 6. Deep coagulopathy (prothrombin time }(\mathrm{PT})>2.5 \text { times the } \\
\text { normative values, activated partial thromboplastin time }(\text { APTT })> \\
2 \text { times the normal or platelet count } \leq 50.000 / \mu \mathrm{l})\end{array}$ \\
\hline & $\begin{array}{l}\text { 7. Non-consolidated } \\
\text { fractures }\end{array}$ & 7. Heparin intravenous infusion $\geq 2 \mathrm{UI} / \mathrm{ml}$ \\
\hline & & 8. Fever or hypothermia \\
\hline & & 9. Anemia \\
\hline & & 10. Neurodegenerative disease \\
\hline & & 11. Musculoskeletal disease \\
\hline
\end{tabular}


therapy intervention in the peripheral muscle will be quantified to control the total volume of stimulus for each patient.

\section{Experimental design Recruitment procedures}

Initially, all hospitalized patients in the ICU will be assessed according to the inclusion criteria of the study. After screening, the legal representative will be interviewed and invited to be a participant in the study. Following consent, the legal representative will answer the functional performance of the basic activities of daily living through the Barthel Index [44] and the quality of life through the Medical Outcome Study 36 - Item Short Form Health Survey (SF-36) questionnaire [45, 46]. Following that, the patient will undergo other initial evaluations (T0) within a 23-h period after admission to the ICU or coma identification in the ICU hospitalization for the baseline demographic characterization, clinical, cardiovascular, and neuromuscular.

\section{Randomization procedures}

Initially, all participants will be pooled into a single group. Afterwards, patients will be classified into quartiles by muscle thickness (MT) of vastus lateralis (VL) and type of critical disease and assigned in a random and counterbalanced way into one of the three training protocols: PM/control, BFRp, or BFRpE using a maximally tolerated imbalance model [47]. MT will be measured exclusively in the right leg. An unpaired $t$ test will be used to ensure that there is no baseline difference between the groups. If significant between-group differences are detected, randomization will be repeated until a random distribution with no difference is achieved [48]. The Berger-Exner test will be applied to verify selection bias [49].

\section{Primary outcome measurements}

Acute cardiovascular responses The first training session (T1) will immediately succeed $\mathrm{T} 0$ and will have the monitoring of acute cardiovascular responses to training. Mean arterial pressure (MAP), central and peripheral systolic blood pressure (SBP [SBPc and SBPp]), and central and peripheral diastolic blood pressure (DBP [DBPc and DBPp]) will be measured by pulse wave analysis. Concomitantly, the heart rate (HR) and peripheral oxygen saturation $\left(\mathrm{SpO}_{2}\right)$ should be recorded through a portable vital signal monitor (Dixtal, DX 2021, Amazonas, Brazil) every $2 \mathrm{~min}$. The mean of 5 recordings at rest (10 min of rest), 18 recordings during exercise $(\sim 37$ min of training), and the average of 5 post-exercise recordings $(10 \mathrm{~min})$ will be considered in the analysis. Electrocardiographic signals will be monitored, and, in case of adverse events, the session will be promptly interrupted. The training protocol will be applied to both legs during the session, simultaneously and alternately between the stimulated leg and the rest of the contralateral limb [37].

Cardiovascular safety and applicability of peripheral muscle training To assess cardiovascular safety, HR values $<50 \mathrm{bpm}$ or $>180 \mathrm{bpm}, \mathrm{SBP}<80 \mathrm{mmHg}$ or $>160$ $\mathrm{mmHg}$, DBP $<60 \mathrm{mmHg}$ or $>80 \mathrm{mmHg}$, MAP $<60$ $\mathrm{mmHg}$ or $>120 \mathrm{mmHg}$, cardiac or respiratory arrythmias, $\mathrm{SpO}_{2}<88 \%$, signals of respiratory discomfort [50, 51 ], or signals of deep venous thrombosis will be considered criteria to interrupt the protocol. Except for the occurrence of deep venous thrombosis, two consecutive training attempts will be performed after the first training interruption before withdrawing the patient from the study. It is suggested for two main reasons: to exclude the possibility of an occasional adverse event due to the variability of the clinical conditions, and to maintain the training frequency in case the patient continues in the study. In case of exclusion, the protocol will be considered unsafe for this patient. However, in case $15 \%$ or more unsafe conditions occur in the same training protocol, the protocol will be excluded from the study. To evaluate the applicability, the number of adverse events and intercurrence will be recorded, and if a total number of adverse events and/or intercurrence overcome $20 \%$ of the total training sessions, or there is deep venous thrombosis occurrence in at least $5 \%$ of the patients, protocols will be considered unsafe and impracticable. If cardiovascular variations are greater than $20 \%$ of the baseline, the protocol will be considered impractical.

\section{Measurement of secondary outcomes}

Neuromuscular adaptations of muscle mass and strength Muscle mass and quality adaptations will be assessed daily prior to the first training session $(\sim 12 \mathrm{~h}$ from the last session) and $12 \mathrm{~h}$ after the last training session (T2) (until $12 \mathrm{~h}$ prior to the coma awakening), to the predicted death or ICU discharge. The muscle mass of the $\mathrm{VL}$, rectus femoris (RF), and anterior tibial (AT) will be measured by MT and muscle quality, by echo intensity, both analyses obtained by ultrasound images. If the patient awakes from a coma and has the appropriate cognition to collaborate in active assessments, the global muscle strength will be evaluated by the Medical Research Council (MRC) score after $12 \mathrm{~h}$ of T2, in the ICU and at hospital discharge. Adequate cognition will be assessed by the absence of delirium after completing the Confusion Assessment Method for Intensive Care Units (CAM-ICU) score [52]. 
Physical function adaptations Physical function will be assessed $12 \mathrm{~h}$ after T2 and in the ICU and at hospital discharge through the Physical Function in Intensive Care Test Scored (PFIT). Lastly, during home follow-up, functional motor performance of basic activities of daily living will be evaluated using the Barthel Index, 6 and 12 months after hospital discharge, by telephone.

Quality of life adaptations Quality of life will be measured simultaneously with basic activities of daily living performance, using the SF-36 questionnaire, which is validated in Portuguese and Brazilian culture and is reliably applicable by telephone $[53,54]$.

\section{Blinding procedures}

To be considered a double-blind study, one of the authors will be assigned to create codes for the trainingrelated adaptation data, in addition to being responsible for the randomization of patients. The evaluator, who evaluates the safety and training-related adaptations, will be blinded to the experimental groups. Each experimental group will be led by a different trainer who will also be blinded for the other training groups. Lastly, participants will be blinded by their coma, and in case the participant awakes from coma, information from the study will be provided, but not about the protocol they had previously undergone.

\section{Study interventions}

\section{Peripheral muscle training}

After T1, in view of the cardiovascular safety and applicability of PM, BFRp, and BFRpE, training sessions will be held twice a day, divided by $4 \mathrm{~h}$ [51]. The starting training leg will be randomly chosen at T1 and, from that, alternated in every training session. Patients will undergo the experimental protocol if they present controlled temperature (between 36.5 and $37.5^{\circ} \mathrm{C}$ ), stable blood pressure ( $>100$ and $<150$ of SBP and $>60$ and $<100$ of DBP), $\mathrm{SpO}_{2}>90 \%$, respiratory rate $(\mathrm{RR})<25 \mathrm{rpm}$, and $\mathrm{HR}>60$ and $<140 \mathrm{bpm}[55]$.

Passive mobilization/control group protocol (PM) The PM protocol will be modified from Barbalho et al. [37]. The authors applied 3 sets of 15 mobilizations for flexion and extension of the hips, knees, and ankles. Movement was standardized in 2:2 using a metronome ( $2 \mathrm{~s}$ flexion and 2 extension), totaling $3 \mathrm{~min}$ of PM. To standardize PM with the BFR protocol, in every minute of PM, 1 min of rest will be allowed, totaling $5 \mathrm{~min}$ of PM for each set. Following that, a 3-min rest will be allowed, and the mobilization will be repeated in 5 sets. The session will last $37 \mathrm{~min}$ on average [56].
Passive mobilization associated with blood flow restriction protocol (BFRp) A pressure cuff with 17.5 $\mathrm{cm}$ of width and $94 \mathrm{~cm}$ of length (JPJ, Sao Paulo, Brazil) with a pressure manometer will be placed on the quadriceps muscle, on the inguinal fold. Afterward, a vascular Doppler probe (DV-600; Martec, Ribeirao Preto, Brazil) will be placed in the posterior tibial artery. To determine the occlusion pressure, the cuff will be inflated until the auscultatory pulse stops [57]. An external compression of $85 \%$ of the total vascular occlusion pressure will be applied for $5 \mathrm{~min}$, followed by a 3-min rest (compression release) [42]. The BFR protocol will be synchronized to the PM protocol. Compression will be repeated 5 times during the training session, and occlusion pressure will be re-evaluated in all sessions.

Passive mobilization associated with blood flow restriction and combined with neuromuscular electrical stimulation (BFRpE) The procedures for BFRp will be adopted and synchronized with an electrical stimulation protocol. For the electrical stimulation electrode placement, the skin will be subjected to trichotomy, abrasion, and asepsis. Rectangular-shaped electrodes $(50 \times 50 \mathrm{~mm})$ will be placed on the distal and proximal motor points of the VL (proximal and distal points located between the reference line of the antero-superior iliac spine and the superior lateral border of the patella and on the line between the apex of the great trochanter and the superior lateral border of the patella, respectively), RF (located on the reference line between the antero-superior iliac spine and the superior patella border), and AT (on the line between the apex of fibular head and the medial malleolus). In addition to the reference lines, the placement of the electrodes demonstrated in Santos et al. [58] and Dirks et al. [59] will be used to guide the location and electrostimulation of VL, RF, and TA. Additionally, this electrode placement will be marked with a semi-permanent pen to maintain the stimulus points throughout the study. A biphasic electro stimulator (Dualpex 071, Quark Medical, Piracicaba, Brazil) will provide symmetric pulses of $100 \mathrm{~Hz}$, pulses lasting $400 \mu \mathrm{s}, 5 \mathrm{~s}$ on $(0.75 \mathrm{~s}$ rise, $3.5 \mathrm{~s}$ contraction and $0.75 \mathrm{~s}$ decay), and $10 \mathrm{~s}$ off, the intensity must be capable of causing visible contractions. The mean intensities used should be maintained from 29 to 33 $\mathrm{mA}$ and increased in approximately $3 \mathrm{~min}$, when muscle contraction is no longer visible. The session will last $40 \mathrm{~min}$, including $30 \mathrm{~min}$ of stimulation, a 5min warm-up, and a 5-min cool-down, both with 5 $\mathrm{Hz}$ of frequency, pulse wave lasting $250 \mu \mathrm{s}$, and submaximal intensities (without muscle contraction) [59, 60]. The same researcher will apply both the BFRp and electrical stimulation. 


\section{Cardiovascular assessment}

\section{Cardiovascular assessment by the pulse wave analysis}

Pulse wave analysis will be performed using SphygmoCor equipment (SphygmoCor, AtCor Medical, Sydney, Australia). In a supine position, the patient will have a pneumatic clamp placed in the proximal portion of the left arm. Following that, additional data such as age, weight, and height will be provided to the system. After a 10-min rest, three measurements of systolic and diastolic arterial pressure will be performed in a 2-min interval [61] and accepted as long as the difference is less than $10 \%$ [62], or $5 \mathrm{mmHg}$ [63] between the measurements. Afterward, the mean value of the three accepted measurements will be inserted into the system to obtain the MAP, SBPc, SBPp, DBPc, and DBPp [64-67]. In $\mathrm{T} 0$, the variables will be measured after $10 \mathrm{~min}$ of rest. In $\mathrm{T} 1$, it will be taken prior $(10 \mathrm{~min})$, during (23 and $37 \mathrm{~min}$ ), and after $(47 \mathrm{~min})$ the training session. The average between minutes 23 and 37 (pause between sets) will be used as the exercise value.

\section{Muscle mass and quality assessment MT and echo intensity ( $M T_{\text {echo }}$ ) by ultrasonography}

$\mathrm{MT}$ and $\mathrm{MT}_{\text {echo }}$ will be measured by ultrasound images (Mysono U6 EX; Samsung Medison, Gangwon-do, South Korea). For body fluid homogenization, 15 min of rest in the supine position will be allowed, with the lower limbs neutrally positioned and sustained by a Velcro strip. A 7.5 MHz linear-array probe (LN5-12; Samsung Medison, Gangwon-do, South Korea), revested by surface gel, to promote acoustic coupling without dermic compression, will be placed longitudinally to the muscle fibers. The anatomic reference between two MT points of each muscle will be defined by the distal motor point sites used for the electrical stimulation. Additionally, for the $\mathrm{VL}$, the anatomical reference will be the middle portion between the great trochanter and the lateral epicondyle [68]. For RF, the reference will be set at 50\% and at twothirds of the distance from the anterior superior iliac spine and the superior patella border [51, 69]. Anatomical references for AT will be defined in one-fourth of the distance between the inferior portion of the patella and the lateral malleolus and one-third of the distance between the border of the fibula and the medial malleolus [70]. Sequential images will be acquired with $6 \mathrm{~cm}$ of depth and, after digitalization, analyzed using the ImageJ software (National Institute of Health, USA). MT (cm) will be characterized as the perpendicular measurement between the superficial and deep aponeurosis [71]. $\mathrm{MT}_{\text {echo }}$ (A.U.) will be evaluated using greyscale grading, obtained by the histogram function of the software $(0=$ black and $256=$ white) [72]. Three consecutive images of the same anatomic point will be analyzed, and the mean will be adopted as the final value for MT and
$\mathrm{MT}_{\text {echo }}$ [73]. $\mathrm{MT}_{\text {echo }}$ will be normalized by MT (i.e., $\left.\mathrm{MT}_{\text {echo }} / \mathrm{MT}, \mathrm{cm}\right)$ to explain the effects of alterations on muscle size [57].

\section{Muscle strength assessment Global muscle strength by MRC score}

Six muscle groups of the upper and lower limbs will be assessed bilaterally through the global strength (shoulder abductors, elbow flexors, wrist extensors, hip flexors, knee extensors, and feet dorsiflexors) by the MRC score $[51,74,75]$. Test familiarization will be performed through passive movements, and the tests will be applied in a fixed order. All muscle groups will be rated from 0 to 5 , where 0 means absence of visible/palpable muscle contraction and 5 means movements performed against gravity and resistance [75]. For the fragile and critical population, patients will be positioned in dorsal decubitus with the headboard angled at $45^{\circ}$. Then, arm abduction will be tested against gravity with the elbow in flexion. In case of a successful attempt, the strength will be rated from 4 to 5 . Otherwise, patients will be repositioned in dorsal decubitus at $10^{\circ}$. to be rated from 0 to 3. Following that, the elbows, wrists, hips, knees, and ankles will be tested. In case any muscle group cannot be evaluated due to a central/peripheral nervous injury or orthopedic problems, the total sum will be calculated by extrapolating the identical contralateral muscle [20]. The weakness acquired from the ICU will be identified from scores $<48$ [76] and classified as severe weakness if $<36$ points [75].

\section{Physical function assessment Physical function by the PFIT scored}

The PFIT scored will be applied to measure the physical function of the ICU patients. The score presents four items (assistance with sit to stand, cadence, strength of the shoulder flexors, and strength of the knee flexors), and for each item, the scoring varies from 0 to 3 . The maximal score is 12, which indicates functional independence [77]. The PFIT scored will be applied through the translated and validated version for the Brazilian population [78].

\section{Physical function by the Barthel Index}

The Barthel Index is widely used in Brazil $[79,80]$ and is applied in severely ill patients [81-83] and administered by telephone $[84,85]$. It comprises 10 items weighted differently. Two items (bathing and personal care) can be graded in two alternatives (0 and 5 points), whereas 6 items (feeding, dressing, bowels [fecal and urinary continence], toilet use, stairs), in three alternatives $(0,5$, and 10 points), and two items (transfers and mobility) present four alternatives $(0,5,10$, and 15 points). The final score 
is obtained by summing each item, varying from 0 (complete dependence) to 100 (independence) [44].

\section{Quality of life assessment \\ Quality of life using the SF-36 questionnaire}

Quality of life will be assessed using the SF-36 questionnaire, an instrument of good acceptance, reliability, and validity for ICU patients validated in Brazil and easily administered by telephone $[45,46,53,54]$. It comprises 8 domains: physical function, role-physical, bodily pain, general health, vitality, social functioning, roleemotional, and mental health. Scores range from 0 to 100 , where 0 corresponds to the worst general health status, and 100 corresponds to the best health condition [86-88]. The categorization and description of the methods and analyses are shown in Table 2.

\section{Statistical analysis}

After data collection, participants will be distributed into subgroups by periods in coma (2, 3-4, 5-6 days), in alertness (1-2, 3-4, 5-6 days), and in ICU permanence (3-4, 5-6, 7-8, 9-10, 11-12 days). The normality of data will be analyzed using the Shapiro-Wilk test. Oneway analysis of variance (ANOVA) will be used for intra-group comparisons in T0. A mixed-model analysis will be used for each dependent variable, whereas group and time will be considered as fixed factors and subject as the random factor. In case of significant $F$, the Tukey adjustment will be applied for multiple comparisons. In the event of a non-normal data distribution, a KruskalWallis test will be applied to test for the differences in baseline values and the Friedman test to analyze the repeated measures. The adjusted $p$ values will be calculated using the Hommel procedure [48]. Effect sizes between and within groups will be calculated using Cohen's $d$ [89]. The minimal clinically important difference will be assessed with distribution-based methods [90]. The statistical significance will be assessed at $p<$ 0.05. All analyses will be performed using R 3.6.2 (The $R$ Project for Statistical Computing, 2019) in R-studio 1.3.443 (RStudio Inc., Boston, MA, USA).

\section{Discussion}

The present study focuses on describing an innovative experimental protocol based on cardiovascular safety, scope of research, and distinct experimental control to compose a randomized controlled clinical trial, which aims to investigate the applicability and the effect of a novel combination of training protocols of peripheral muscle atrophy and weakness, functional adaptations and on quality of life in severely ill comatose patients and within after 12 months of hospital discharge.

The innovative initial aspects of the study involved the purpose of optimizing the combination of training protocols for severely ill comatose patients. The first protocol consisted of an adaptation of a recently applied protocol, comprising PM and BFR [37] adjusted to the current BFR recommendations [42], aiming to reduce muscle atrophy and weakness. The second purpose included a novel combination involving electrical stimulation, which is widely applied in ICUs $[7,8]$, with PM and BFR [37] to prevent muscle atrophy and weakness and maximize the functional adaptations and the quality of life, as well as its return to household and social activities.

In addition to using an innovative combination, the experimental design was modified from the intra-subject design, used by previous studies in the field such as

Table 2 Categorization and description of the methods and analyses of the study variables

\begin{tabular}{|c|c|c|c|}
\hline $\begin{array}{l}\text { Evaluation } \\
\text { category }\end{array}$ & Organic responses & Method of evaluation & Variables in analyses \\
\hline $\begin{array}{l}\text { Safety and } \\
\text { applicability }\end{array}$ & Acute cardiovascular & Pulse wave analysis (PWA) & $\begin{array}{l}\text { MAP, SBPc, SBPp, DBPC, } \\
\text { and DBPp (mmHg) }\end{array}$ \\
\hline $\begin{array}{l}\text { Safety and } \\
\text { applicability }\end{array}$ & Acute cardiovascular & Analyses of the vital signs & $\mathrm{HR}(\mathrm{bpm})$ and $\mathrm{SpO}_{2}(\%)$ \\
\hline Muscle systems & Muscle mass adaptation & Ultrasound image & Muscle thickness (cm) \\
\hline Muscle systems & Muscle quality adaptation & Ultrasound image & $\begin{array}{l}\text { Echo intensity (A. U. from } \\
0 \text { to 256) }\end{array}$ \\
\hline $\begin{array}{l}\text { Neuromuscular } \\
\text { systems }\end{array}$ & Global muscle strength adaptations & Medical Research Council (MRC) Score & Number scoring (0 to 60 ) \\
\hline $\begin{array}{l}\text { Physical } \\
\text { function }\end{array}$ & Adaptations in physical function in ICU & Physical Function in the Intensive Care Test Scored (PFIT) & Number scoring (0 to 12 ) \\
\hline $\begin{array}{l}\text { Physical } \\
\text { function }\end{array}$ & $\begin{array}{l}\text { Adaptations in physical functional } \\
\text { performance after hospital discharge }\end{array}$ & $\begin{array}{l}\text { Performance in the basic activities of daily living by the } \\
\text { Barthel Index (BI) by telephone interview }\end{array}$ & $\begin{array}{l}\text { Number scoring (0 to } \\
100)\end{array}$ \\
\hline $\begin{array}{l}\text { Clinical } \\
\text { outcomes }\end{array}$ & Adaptations in quality of life & $\begin{array}{l}\text { Medical Outcome Study } 36 \text { - Item Short Form Health } \\
\text { Survey (SF-36) questionnaire }\end{array}$ & $\begin{array}{l}\text { Number scoring (0 to } \\
100)\end{array}$ \\
\hline
\end{tabular}

$S B P C$ central systolic blood pressure, SBPp peripheral systolic blood pressure, $D B P C$ central diastolic blood pressure, $D B P p$ peripheral diastolic blood pressure, HR heart rate, MAP mean arterial pressure, $\mathrm{SpO}_{2}$ peripheral oxygen saturation, ICU intensive care unit 
Dirks et al. [59], Barbalho et al. [37], and Chhetri et al. [51], to an inter-subject design. The inter-subject design enables the application of protocols bilaterally, simultaneously, and alternately, which allows the replication of the intensive care clinical practice and preserves the ecological validity and investigation of the maximized effects of training on muscle atrophy and weakness, functional responses, and outcome of quality of life of ICU coma surviving patients.

By replicating the intensive care practice, a combination of PM, BFR, and electrical stimulation applied bilaterally, simultaneously, and even alternately will promote unknown cardiovascular responses, which may be investigated as a guarantee of vital safety of the critical patients during the physiological stress imposed by the exercise. Based on that, the present study aimed to measure the cardiovascular responses during and after the first training session, despite the absence of intercurrence or adverse events reported during passive BFR and BFRp, or electrical isolated stimulation [37, 59].

Concerning the scope of the investigation, in addition to the daily assessment of muscle mass, we also proposed a broad assessment of the strength, physical function, and quality of life of the ICU coma surviving patients. Thus, we suggest not only assessing the isolated muscular system in the ICU, but also monitoring the functional integration of the systems through functional analysis and the outcome of quality of life.

For muscle mass, the option of measuring the MT by ultrasound images was based on the scientific validation of this method, which is quicker and simpler for bedside conditions than the cross-sectional area assessment [91]. Additionally, MT presents lower measurement errors such as the coefficient of variation and the typical error, when compared to the muscle cross-section area. The elevated coefficient of variation and typical errors demonstrate high variability between two consecutive measurements, which precludes the detection of daily changes in muscle mass in comatose patients. As a consequence, non-detection of slight changes could impair the management of muscle atrophy prevention, and therefore, the clinical evolution of the patients [92].

In addition to the assessment of muscle mass, muscle quality was evaluated using the $\mathrm{MT}_{\text {echo }}$ analysis. This method consists of classifying the ultrasound images through greyscale grading, which varies from 0 to 256, where 0 means low gray coloration and 256, intensive gray coloration and characterizes the presence of edema, fat or healthy muscle tissue [72]. Thus, in addition to muscle mass, ultrasound images can assess muscle quality, which involves not only muscle fibers, but also the presence of inflammatory liquid and/or intramuscular fibrosis acquired from low mobility changes, intensive therapy strategies, and exercise-related muscle damage. Additionally, muscle quality assessment allows normalization of MT to the respective echo intensity. This strategy overlooks changes in edema or fibrosis in the MT results, suggesting that the promoted changes are mainly due to the real effect of resistance training on muscle mass [93].

To test muscle strength, the MRC score was applied, which is the gold standard assessment for global strength [74]. This method was suggested to evaluate the muscle strength of patients that awake from coma until hospital discharge. Thus, we were concerned with monitoring the neuromuscular evolution of the critical patient, targeting it to analyze the effect of training during the whole hospitalization stay.

Consecutively, the physical function measurement was described to evaluate the interaction of the neuromuscular system with the other organic systems. Thus, we suggested applying the PFIT scored while awake from coma and ICU and hospital discharge. In addition, the Barthel Index was suggested to assess physical performance during the recovery process at home, as it is validated for use through telephone contact $[80,94]$.

Thus, an evaluation of the clinical outcome after 6 and 12 months of hospital discharge was also structured in the system's functional integration to evaluate the household and social reinsertion of patients surviving ICU coma. The rationale of our choice was based on associating muscle strength loss with the worsening of quality of life [27, 29-31, 95]. From this, the follow-up of the clinical outcome was suggested through the SF36 questionnaire.

In addition to suggesting a broad and integral approach to neuromuscular and systemic functional assessments, the inclusion criteria and the experimental design were based on the largest possible number of methodological control conditions. Thus, for the inclusion criteria, the preference for comatose adults was essential for better control of the population in question.

More specifically, our objective was to ensure that the muscular evaluation was performed during the longest period of bed restriction, in which muscle atrophy and weakness occurred [15, 17, 32]. Finally, patient admission was based on a moderate to severe coma classification, aiming to avoid different volumes of active contractions and, consequently, different stimuli in muscle protein syntheses, which would promote a high variability in responses to the study of muscular variables.

Regarding the trial design, the inclusion of patients within the first $18 \mathrm{~h}$ of coma identification was suggested to promote a higher experimental control. The aim of this was to ensure that there would be enough time to perform the admission procedures and the first training session, before the beginning of the deleterious effects associated with low mobility $[15,16]$. 
Another control that was adopted was the randomization of patients into experimental groups by ranking the characteristics that could impair the between-group comparison. More specifically, a peculiar aspect of intensive care studies is the high variability of the sample characteristics, principally in adult ICUs, where the admission involves non-pediatric patients of both sexes, with all types of clinical severe illness, preand post-surgery. Thus, to homogenize the experimental groups, we purposely stratified the participants into quartiles, considering MT and type of disease.

To further enhance trial control, our study also proposed daily assessments involving muscle mass. This strategy enables a detailed and trustworthy monitoring of the training-related responses, which differs from specific evaluations, performed during the pre- and posttraining period. In addition, this strategy may be important for the experimental and statistical adequacy of the clinical trial to intensive care, in which daily pre- and post-session assessments allow lower experimental losses. Thus, in the event of unanticipated patient discharge or death, the statistical analysis may include the last assessment data from the previous day.

Despite the positive aspects presented, the study is not without limitations. The inclusion of patients with varied duration of coma (2-6 days of intervention and 2 to 12 days of ICU permanence) may lead to high heterogeneity at both time points. As an alternative, the use of subgroups for the duration of the coma $(2-3,4-5$, and 6 days), alertness (1-2, 3-4, and 5-6), and the time of stay in the ICU $(3-4,5-6,7-8,9-10$, and 11-12) was suggested. Finally, the patients who were not classified in the study groups or in the added subgroups should be included in the clinical trial flowchart, but not in the statistical analysis.

From the promising and novel optimizing association of early mobilization protocols with comatose patients in the ICU, using broad methods of clinical monitoring and methodological control, the present study promoted a wide, integral, innovative, and viable experimental protocol to a future randomized controlled clinical trial, aiming to reproduce new scientific evidence regarding early mobilization in critical care. More specifically, our study enabled the investigation of cardiovascular safety, applicability, and effects of innovative peripheral motor interventions to prevent muscle atrophy and weakness, reduced physical function, and low quality of life, which were monitored since coma until health recovery with 12 months of hospital discharge.

Thus, we expect to contribute to the clinical practice of early passive mobilization in critically comatose patients through the purpose of maximizing the effects of an optimized interventional protocol and, consequently, cooperating for musculoskeletal rehabilitation and functional reinsertion in the home and social activities of survivors of coma in ICUs.

\section{Trial status}

This manuscript is based on the most recent version of the protocol (4 April 2020). The study was opened to recruitment at the ReBec site in April 2020, and the first participant was recruited in the same month. Recruitment was expected to be completed in October 2020; however, an insufficient number of participants was recruited due to the current pandemic scenario. In this regard, recruitment was suspended during the pandemic quarantine period in Brazil which explains the delay in submitting the study to this journal.

\section{Abbreviations}

ICU: Intensive care unit; PM: Passive mobilization; BFR: Blood flow restriction; BFRp: Blood flow restriction associated with passive mobilization; BFRpE: Blood flow restriction associated with passive mobilization and combined with electrical stimulation; T0: Baseline; T1: First training session; T2: Last training session; SPIRIT: Standard Protocol Items: Recommendations for Interventional Trials; NRS-2002: Nutritional Risk Screening 2002; SF36: Medical Outcome Study 36 - Item Short Form Health Survey; MT: Muscle thickness; VL: Vastus lateralis; SBP: Systolic blood pressure; SBPc: Central systolic blood pressure; SBPp: Peripheral systolic blood pressure;

DBP: Diastolic blood pressure; DBPC: Central diastolic blood pressure; DBPp: Peripheral diastolic blood pressure; HR: Heart rate; MAP: Mean arterial pressure; $\mathrm{SpO}_{2}$ : Peripheral oxygen saturation; RF: Rectus femoris; AT: Anterior tibial; MRC: Medical Research Council; CAM-ICU: Confusion Assessment Method for Intensive Care Units; PFIT: Physical Function in Intensive Care Test Scored; RR: Respiratory rate; MT echo: Echo intensity; ANOVA: Analysis of variance; SD: Standard deviation; ReBec: Brazilian Clinical Trial Registry; UFSCar: Federal University of São Carlos; CAPES: Coordination for the Improvement of Higher Education Personnel; LACAP: Cardiopulmonary Physiotherapy Laboratory; MUSCULAB: Laboratory of Neuromuscular Adaptations to Resistance Training

\section{Supplementary Information}

The online version contains supplementary material available at https://doi. org/10.1186/s13063-021-05916-z.

Additional file 1. SPIRIT 2013 Checklist: Recommended items to address in a clinical trial protocol and related documents*.

\section{Acknowledgements}

The authors acknowledge the Federal University of Sao Carlos (UFSCar), the Center of Biological and Health Sciences, the Department of Physiotherapy and Post-Graduate Program in Physiotherapy, the Cardiopulmonary Physiotherapy Laboratory (LACAP), and the Laboratory of Neuromuscular Adaptations to Resistance Training (MUSCULAB) for the structural, academic, and scientific support to the elaboration of the manuscript. The authors also express deep gratitude to the coordination team of the Irmandade da Santa Casa da Misericórdia de São Carlos; members of the ethics, teaching, and research committees; the adult intensive care unit and their coordinators; and the medical, nursing, and physiotherapy teams for the scientific, learning, and support for developing the study and the future clinical trial. In particular, we would also like to thank the Coordination for the Improvement of Higher Education Personnel (CAPES) for the scholarship awarded to TMPCB.

\section{Data sharing}

All data from the future clinical trial will be recorded in an electronic and access-controlled repository of the ReBec immediately after the end of each stage of the study, as recommended in the filling instructions of the ReBec platform. Thereafter, such data will be publicly and electronically shared through the mensal update of the ReBec platform for international 
disclosure-in the International Clinical Trials Registry Platform (ICTRP). Hence, all data will be managed in the repository by the main researcher in conjunction with the study team, to guarantee authenticity, accuracy, and integrality of the public data sharing. Additionally, the anonymity of all participants will be ensured by the controlled access of the information, determined by the ReBec platform, and by the administration of the physical documents by the study team. In this regard, all confidential documents will be preserved in a safe and specific storage site. Finally, after 6 years of clinical trial development, documents will be safely extinguished.

\section{Dissemination}

The results of the future clinical trial will be disseminated in scientific journals in the field and presented in national and international conferences in intensive care. For popular dissemination, a summary of the objectives and results prepared by a committee comprising study representatives and patients will be posted on the hospital's bulletin board and website, in addition to the Research Laboratory and University media pages.

\section{Authors' contributions}

TMPCB elaborated the scientific question and experimental design, selected the adequate methods of the analyses, and developed all the versions of the manuscript. CAL advised the refinement of the study questions, scientific hypotheses, experimental design, selection, and theoretical foundation of the experimental protocol methods and was enrolled in all the writing outcomes of the manuscript. JCBJ advised the medical discussion of the experimental design and the teaching of adequate methods of the analyses to answer the scientific question. Similar to JCBJ, FRC also participated in the discussion and in teaching the methods to the other members of the team and contributed to the experimental design. NGM and TRS were involved in the development of the experimental design and discussion, teaching, and learning experimental protocol methods. ABS participated in the refinement of the scientific question, experimental design, and selection of the methods of the analyses. Lastly, RGM advised the refinement of the scientific question, experimental design, theoretical foundation of the methods of the analyses, and writing outcomes of the manuscript. All authors read and approved the final version of the manuscript.

\section{Funding}

This study did not receive any donations from public, commercial, or nonprofitable funding agencies. Financial support was provided to TMPCB throughout the PhD scholarship from the Coordination for the Improvement of Higher Education Personnel (CAPES) - Brazil - Finance Code 001.

\section{Availability of data and materials}

The datasets supporting the conclusions of this article are available in the repository of the ReBec (http://www.ensaiosclinicos.gov.br), registration number RBR-2qpyxf.

\section{Declarations}

\section{Ethics approval and consent to participate}

The study was approved by the Ethics Committee at the Federal University of Sao Carlos (UFSCar) (CAAE 77746917.8.000.5504; Process $n^{\circ} 2.498 .317$ ) and the Irmandade da Santa Casa de Misericórdia de São Carlos (CAAE 77746917.8.3001.8148; Process $n^{\circ}$ 3.419.587). The study will be conducted in conformity with the Resolution $n^{\circ} 466 / 12$ of the Brazilian National Council of Health. The inclusion of the patients will be conditioned on the signature of the informed consent by a member of the family or legal representative who will be informed about the research details and the preservation of the identity of the patient. In case the patient reestablishes a vigil condition, the study details will be presented to receive the informed content from the participant. The information and data will be excluded in case the participant prefers to stop participating in the study.

\section{Consent for publication}

By giving their written informed consent, participants have given their consent for data storage and publication of the study results. All authors consented to publication.

\section{Competing interests}

The authors declare that they have no competing interests.

\section{Author details}

${ }^{1}$ Cardiopulmonary Physical Therapy Laboratory, Department of Physical Therapy, Federal University of São Carlos, Rod. Washington Luiz, km 235 - SP 310, CEP 13565-905, São Carlos, Brazil. ²Laboratory of Neuromuscular Adaptations to Resistance Training, Department of Physical Education, Federal University of São Carlos, São Carlos, Brazil. 'Department of Medicine, Federal University of São Carlos, São Carlos, Brazil. ${ }^{4}$ Department of Anesthesiology and Intensive Care Unit at the Irmandade da Santa Casa de Misericórdia de São Carlos, São Carlos, Brazil.

\section{Received: 13 December 2020 Accepted: 6 December 2021}

Published online: 30 December 2021

\section{References}

1. de Jonghe B, Lacherade JC, Sharshar T, Outin H. Intensive care unit-acquired weakness: risk factors and prevention. Crit Care Med. 2009;37(10 Suppl): S309-15. https://doi.org/10.1097/CCM.0b013e3181b6e64c.

2. Lanken PN, Terry PB, Adler DC, Brooks-Brunn JA, Crawford SW, Danis M. Fair allocation of intensive care unit resources. American Thoracic Society. Am J Respir Crit Care Med. 1997;156(4 Pt 1):1282-301.

3. Sprung CL, Danis M, lapichino G, Artigas A, Kesecioglu J, Moreno R, et al. Triage of intensive care patients: identifying agreement and controversy. Intensive Care Med. 2013;39(11):1916-24. https://doi.org/10.1007/s00134013-3033-6.

4. Callen BL, Mahoney JE, Grieves CB, Wells TJ, Enloe M. Frequency of hallway ambulation by hospitalized older adults on medical units of an academic hospital. Geriatr Nurs. 2004;25(4):212-7. https://doi.org/10.1016/j.gerinurse.2 004.06.016.

5. Vollman KM. Introduction to progressive mobility. Crit Care Nurse. 2010; 30(2):S3-5. https://doi.org/10.4037/ccn2010803.

6. Morris $P E$, Herridge MS. Early intensive care unit mobility: future directions Crit Care Clin. 2007;23(1):97-110. https://doi.org/10.1016/j.ccc.2006.11.010.

7. Cameron S, Ball I, Cepinskas G, Choong K, Doherty TJ, Ellis CG, et al. Early mobilization in the critical care unit: a review of adult and pediatric literature. J Crit Care. 2015;30(4):664-72. https://doi.org/10.1016/j.jcrc.2015.03.032.

8. Koukourikos K, Tsaloglidou A, Kourkouta L. Muscle atrophy in intensive care unit patients. Acta Inform Med. 2014;22(6):406-10. https://doi.org/10.5455/a im.2014.22.406-410.

9. Snijders T, Wall BT, Dirks ML, Senden JMG, Hartgens F, Dolmans J, et al. Muscle disuse atrophy is not accompanied by changes in skeletal muscle satellite cell content. Clin Sci (Lond). 2014;126(8):557-66. https://doi.org/10.1 042/CS20130295.

10. Kortebein P, Ferrando A, Lombeida J, Wolfe R, Evans WJ. Effect of 10 days of bed rest on skeletal muscle in healthy older adults. JAMA. 2007;297(16): 1772-4. https://doi.org/10.1001/jama.297.16.1772-b.

11. Latronico N, Bolton CF. Critical illness polyneuropathy and myopathy: a major cause of muscle weakness and paralysis. Lancet Neurol. 2011;10(10): 931-41. https://doi.org/10.1016/S1474-4422(11)70178-8.

12. Schweickert WD, Hall J. ICU-acquired weakness. Chest. 2007;131(5):1541-9. https://doi.org/10.1378/chest.06-2065.

13. Puthucheary Z, Rawal J, Ratnayake G, Harridge S, Montgomery H, Hart N. Neuromuscular blockade and skeletal muscle weakness in critically ill patients: time to rethink the evidence? Am J Respir Crit Care Med. 2012; 185(9):911-7. https://doi.org/10.1164/rccm.201107-13200E.

14. Hermans $G$, De Jonghe B, Bruyninckx F, Van den Berghe G. Clinical review: critical illness polyneuropathy and myopathy. Crit Care. 2008;12(6):238. https://doi.org/10.1186/cc7100.

15. Gruther W, Benesch T, Zorn C, Paternostro-Sluga T, Quittan M, Fialka-Moser $\checkmark$, et al. Muscle wasting in intensive care patients: ultrasound observation of the M. quadriceps femoris muscle layer. J Rehabil Med. 2008;40(3):185-9. https://doi.org/10.2340/16501977-0139.

16. Ferrando AA, Lane HW, Stuart CA, Davis-Street J, Wolfe RR. Prolonged bed rest decreases skeletal muscle and whole body protein synthesis. Am J Physiol. 1996;270(4 Pt 1):E627-33. https://doi.org/10.1152/ajpendo.1996.2 70.4.E627.

17. Ten Haaf D, Hemmen B, van de Meent H, Bovend'Eerdt TJH. The magnitude and time course of muscle cross-section decrease in intensive care unit patients. Am J Phys Med Rehabil. 2017;96(9):634-8. https://doi.org/10.1097/ PHM.0000000000000711.

18. Fan E, Dowdy DW, Colantuoni E, Mendez-Tellez PA, Sevransky JE, Shanholtz C, et al. Physical complications in acute lung injury survivors: a two-year 
longitudinal prospective study. Crit Care Med. 2014;42(4):849-59. https://doi. org/10.1097/CCM.0000000000000040.

19. Appleton RT, Kinsella J, Quasim T. The incidence of intensive care unitacquired weakness syndromes: a systematic review. J Intensive Care Soc. 2015;16(2):126-36. https://doi.org/10.1177/1751143714563016.

20. De Jonghe B, Sharshar T, Lefaucheur JP, et al. Paresis acquired in the intensive care unit: a prospective multicenter study. Jama. 2002;288(22): 2859-67. https://doi.org/10.1001/jama.288.22.2859.

21. Joyner MJ, Green DJ. Exercise protects the cardiovascular system: effects beyond traditional risk factors. J Physiol. 2009;587(Pt 23):5551-8. https://doi. org/10.1113/jphysiol.2009.179432.

22. Cooke WH, Salinas J, Convertino VA, Ludwig DA, Hinds D, Duke JH, et al. Heart rate variability and its association with mortality in prehospital trauma patients. J Trauma. 2006;60(2):363-70; discussion 370. https://doi.org/10.1 097/01.ta.0000196623.48952.0e

23. Widlansky ME, Gokce N, Keaney JF Jr, Vita JA. The clinical implications of endothelial dysfunction. J Am Coll Cardiol. 2003:42(7):1149-60. https://doi. org/10.1016/S0735-1097(03)00994-X.

24. Norris PR, Ozdas A, Cao H, Williams AE, Harrell FE, Jenkins JM, et al. Cardiac uncoupling and heart rate variability stratify ICU patients by mortality: a study of 2088 trauma patients. Ann Surg. 2006;243(6):804-12; discussion 812-804. https://doi.org/10.1097/01.sla.0000219642.92637.fd.

25. Herridge MS, Tansey CM, Matte A, et al. Functional disability 5 years after acute respiratory distress syndrome. N Engl J Med. 2011;364(14):1293-304. https://doi.org/10.1056/NEJMoa1011802.

26. Iwashyna TJ, Ely EW, Smith DM, Langa KM. Long-term cognitive impairment and functional disability among survivors of severe sepsis. JAMA. 2010; 304(16):1787-94. https://doi.org/10.1001/jama.2010.1553.

27. Wieske L, Dettling-Ihnenfeldt DS, Verhamme C, Nollet F, van Schaik IN, Schultz MJ, et al. Impact of ICU-acquired weakness on post-ICU physical functioning: a follow-up study. Crit Care. 2015;19(1):196. https://doi.org/10.11 86/s13054-015-0937-2.

28. Kress JP, Hall JB. ICU-acquired weakness and recovery from critical illness. N Engl J Med. 2014;371(3):287-8. https://doi.org/10.1056/NEJMc1406274.

29. Hodgson C, Bellomo R, Berney S, et al. Early mobilization and recovery in mechanically ventilated patients in the ICU: a bi-national, multi-centre, prospective cohort study. Crit Care. 2015;19(1):81. https://doi.org/10.1186/ s13054-015-0765-4.

30. Hermans $G$, Van Mechelen H, Clerckx B, et al. Acute outcomes and 1-year mortality of intensive care unit-acquired weakness. A cohort study and propensity-matched analysis. Am J Respir Crit Care Med. 2014;190(4):410-20. https://doi.org/10.1164/rccm.201312-22570C.

31. Garnacho-Montero J, Madrazo-Osuna J, Garcia-Garmendia JL, et al. Critical illness polyneuropathy: risk factors and clinical consequences. A cohort study in septic patients. Intensive Care Med. 2001;27(8):1288-96. https://doi. org/10.1007/s001340101009.

32. De Jonghe B, Cook D, Appere-De-Vecchi C, Guyatt G, Meade M, Outin H. Using and understanding sedation scoring systems: a systematic review. Intensive Care Med. 2000;26(3):275-85. https://doi.org/10.1007/s001340051150.

33. Reith FC, Van den Brande R, Synnot A, Gruen R, Maas Al. The reliability of the Glasgow Coma Scale: a systematic review. Intensive Care Med. 2016; 42(1):3-15. https://doi.org/10.1007/s00134-015-4124-3.

34. Meesen RL, Dendale P, Cuypers K, et al. Neuromuscular electrical stimulation as a possible means to prevent muscle tissue wasting in artificially ventilated and sedated patients in the intensive care unit: a pilot study. Neuromodulation. 2010;13(4):315-20; discussion 321. https://doi.org/1 $0.1111 / j .1525-1403.2010 .00294 . x$

35. Maffiuletti NA, Roig M, Karatzanos E, Nanas S. Neuromuscular electrical stimulation for preventing skeletal-muscle weakness and wasting in critically ill patients: a systematic review. BMC Med. 2013;11(1):137. https://doi.org/1 0.1186/1741-7015-11-137.

36. Burke D, Gorman E, Stokes D, Lennon O. An evaluation of neuromuscular electrical stimulation in critical care using the ICF framework: a systematic review and meta-analysis. Clin Respir J. 2016;10(4):407-20. https://doi.org/1 $0.1111 /$ crj.12234.

37. Barbalho M, Rocha AC, Seus TL, Raiol R, Del Vecchio FB, Coswig VS. Addition of blood flow restriction to passive mobilization reduces the rate of muscle wasting in elderly patients in the intensive care unit: a within-patient randomized trial. Clin Rehabil. 2018;269215518801440.

38. Ganesan G, Cotter JA, Reuland W, Cerussi AE, Tromberg BJ, Galassetti P. Effect of blood flow restriction on tissue oxygenation during knee extension. Med Sci Sports Exerc. 2015;47(1):185-93. https://doi.org/10.1249/ MSS.0000000000000393.

39. Abe T, Loenneke JP, Fahs CA, Rossow LM, Thiebaud RS, Bemben MG. Exercise intensity and muscle hypertrophy in blood flow-restricted limbs and non-restricted muscles: a brief review. Clin Physiol Funct Imaging. 2012; 32(4):247-52. https://doi.org/10.1111/j.1475-097X.2012.01126.X.

40. Gorgey AS, Timmons MK, Dolbow DR, Bengel J, Fugate-Laus KC, Michener $L A$, et al. Electrical stimulation and blood flow restriction increase wrist extensor cross-sectional area and flow meditated dilatation following spinal cord injury. Eur J Appl Physiol. 2016;116(6):1231-44. https://doi.org/10.1007/ s00421-016-3385-z.

41. Loenneke JP, Fahs CA, Rossow LM, Abe T, Bemben MG. The anabolic benefits of venous blood flow restriction training may be induced by muscle cell swelling. Med Hypotheses. 2012;78(1):151-4. https://doi.org/10.1 016/j.mehy.2011.10.014,

42. Patterson SD, Hughes L, Warmington S, Burr J, Scott BR, Owens J, et al. Blood flow restriction exercise position stand: considerations of methodology, application, and safety. Front Physiol. 2019;10:533. https://doi. org/10.3389/fphys.2019.00533.

43. Lancaster GA, Dodd S, Williamson PR. Design and analysis of pilot studies: recommendations for good practice. J Eval Clin Pract. 2004;10(2):307-12. https://doi.org/10.1111/j..2002.384.doc.x.

44. Mahoney Fl, Barthel DW. Functional evaluation: the Barthel Index. Md State Med J. 1965;14:61-5.

45. Cantarelli FB, Szejnfeld VL, Oliveira LM, Ciconelli RM, Ferraz MB. Quality of life in patients with osteoporosis fractures: cultural adaptation, reliability and validity of the Osteoporosis Assessment Questionnaire. Clin Exp Rheumatol. 1999;17(5):547-51.

46. Cuthbertson BH, Scott J, Strachan M, Kilonzo M, Vale L. Quality of life before and after intensive care. Anaesthesia. 2005;60(4):332-9. https://doi.org/1 0.1111/j.1365-2044.2004.04109.x.

47. Berger WW, Ivanova A, Knoll MD. Minimizing predictability while retaining balance through the use of less restrictive randomization procedures. Stat Med. 2003;22(19):3017-28. https://doi.org/10.1002/sim.1538.

48. Nobrega SR, Chacha SGF, Libardi CA. Resistance training combined with blood flow restriction in cirrhosis: study protocol for a randomized controlled trial. Trials. 2020;21 (1):446. https:/doi.org/10.1186/s13063-020-04410-2.

49. Berger WW, Exner DV. Detecting selection bias in randomized clinical trials. Control Clin Trials. 1999;20(4):319-27. https://doi.org/10.1016/S0197-24 56(99)00014-8.

50. Dantas $C M$, Silva PF, Siqueira FH, et al. Influence of early mobilization on respiratory and peripheral muscle strength in critically ill patients. Rev Bras Ter Intensiva. 2012;24(2):173-8. https://doi.org/10.1590/S0103-507X2012000200013.

51. Chhetri I, Hunt JEA, Mendis JR, Patterson SD, Puthucheary ZA, Montgomery $H E$, et al. Repetitive vascular occlusion stimulus (RVOS) versus standard care to prevent muscle wasting in critically ill patients (ROSProx): a study protocol for a pilot randomised controlled trial. Trials. 2019;20(1):456. https:// doi.org/10.1186/s13063-019-3547-5.

52. Gusmao-Flores D, Salluh JI, Dal-Pizzol F, et al. The validity and reliability of the Portuguese versions of three tools used to diagnose delirium in critically ill patients. Clinics (Sao Paulo). 2011;66(11):1917-22.

53. Heyland DK, Hopman W, Coo H, Tranmer J, McColl MA. Long-term healthrelated quality of life in survivors of sepsis. Short Form 36: a valid and reliable measure of health-related quality of life. Crit Care Med. 2000;28(11): 3599-605. https://doi.org/10.1097/00003246-200011000-00006.

54. Chrispin PS, Scotton H, Rogers J, Lloyd D, Ridley SA. Short Form 36 in the intensive care unit: assessment of acceptability, reliability and validity of the questionnaire. Anaesthesia. 1997;52(1):15-23. https://doi.org/10.1111/j.1365-2 044.1997.015-az014.x.

55. Harris $\mathrm{CL}$, Shahid S. Physical therapy-driven quality improvement to promote early mobility in the intensive care unit. Proc (Bayl Univ Med Cent). 2014;27(3):203-7. https://doi.org/10.1080/08998280.2014.11929108.

56. Takarada Y, Takazawa H, Ishii N. Applications of vascular occlusion diminish disuse atrophy of knee extensor muscles. Med Sci Sports Exerc. 2000;32(12): 2035-9. https://doi.org/10.1097/00005768-200012000-00011.

57. Biazon T, Ugrinowitsch C, Soligon SD, et al. The association between muscle deoxygenation and muscle hypertrophy to blood flow restricted training performed at high and low loads. Front Physiol. 2019;10:446. https://doi. org/10.3389/fphys.2019.00446.

58. Dos Santos FV, Cipriano G Jr, Vieira L, et al. Neuromuscular electrical stimulation combined with exercise decreases duration of mechanical 
ventilation in ICU patients: a randomized controlled trial. Physiother Theory Pract. 2018;36(5):1-9. https://doi.org/10.1080/09593985.2018.1490363.

59. Dirks ML, Hansen D, Van Assche A, Dendale P, Van Loon LJ. Neuromuscular electrical stimulation prevents muscle wasting in critically ill comatose patients. Clin Sci (Lond). 2015;128(6):357-65. https://doi.org/10.1042/CS2014 0447.

60. Gerovasili V, Stefanidis K, Vitzilaios K, Karatzanos E, Politis P, Koroneos A, et al. Electrical muscle stimulation preserves the muscle mass of critically ill patients: a randomized study. Crit Care. 2009;13(5):R161. https://doi.org/1 $0.1186 /$ cc8123.

61. Polonia J, Barbosa L, Silva JA, Rosas M. Improvement of aortic reflection wave responses 6 months after stopping smoking: a prospective study. Blood Press Monit. 2009;14(2):69-75. https://doi.org/10.1097/MBP.0b013e32 832941ea.

62. Willum-Hansen T, Staessen JA, Torp-Pedersen C, et al. Prognostic value of aortic pulse wave velocity as index of arterial stiffness in the general population. Circulation. 2006;113(5):664-70. https://doi.org/10.1161/CIRCULA TIONAHA.105.579342.

63. Tai YL, Marshall EM, Glasgow A, Parks JC, Sensibello L, Kingsley JD. Pulse wave reflection responses to bench press with and without practical blood flow restriction. Appl Physiol Nutr Metab. 2019;44(4):341-7. https://doi.org/1 0.1139/apnm-2018-0265.

64. Zanchetti A, Mancia G. Structural cardiovascular adaptation and the consequences for baroreflexes. Hypertension. 1984;6(6 Pt 2):III93-9. https:// doi.org/10.1161/01.HYP.6.6_Pt_2.III93.

65. Garnier AS, Briet M. Arterial stiffness and chronic kidney disease. Pulse (Basel). 2016;3(3-4):229-41. https://doi.org/10.1159/000443616.

66. Brunner EJ, Shipley MJ, Witte DR, Singh-Manoux A, Britton AR, Tabak AG, et al. Arterial stiffness, physical function, and functional limitation: the Whitehall II Study. Hypertension. 2011;57(5):1003-9. https://doi.org/10.1161/ HYPERTENSIONAHA. 110.168864

67. Gel'tser BI, Brodskaia TA. Central arterial pressure in patients with chronic obstructive pulmonary disease. Ter Arkh. 2008;80(3):15-9.

68. Lixandrão ME, Ugrinowitsch C, Bottaro M, Chacon-Mikahil MPT, Cavaglieri $\mathrm{CR}$, Min LL, et al. Vastus lateralis muscle cross sectional area ultrasonography validity for image-fitting in humans. J Strength Cond Res. 2014;28(11):32937. https://doi.org/10.1519/JSC.0000000000000532.

69. Seymour JM, Ward K, Sidhu PS, Puthucheary Z, Steier J, Jolley CJ, et al. Ultrasound measurement of rectus femoris cross-sectional area and the relationship with quadriceps strength in COPD. Thorax. 2009;64(5):418-23. https://doi.org/10.1136/thx.2008.103986.

70. Silva PE, Maldaner V, Vieira L, de Carvalho KL, Gomes H, Melo P, et al. Neuromuscular electrophysiological disorders and muscle atrophy in mechanically-ventilated traumatic brain injury patients: new insights from a prospective observational study. J Crit Care. 2018:44:87-94. https://doi.org/1 0.1016/j.jcrc.2017.10.026.

71. Scanlon TC, Fragala MS, Stout JR, Emerson NS, Beyer KS, Oliveira LP, et al. Muscle architecture and strength: adaptations to short-term resistance training in older adults. Muscle Nerve. 2013;49(4):584-92. https://doi.org/10.1 002/mus.23969.

72. Fukumoto Y, Ikezoe T, Yamada Y, Tsukagoshi R, Nakamura M, Mori N, et al. Skeletal muscle quality assessed from echo intensity is associated with muscle strength of middle-aged and elderly persons. Eur J Appl Physiol. 2012;112(4):1519-25. https://doi.org/10.1007/s00421-011-2099-5.

73. Alvarez IF, Damas F, Biazon TMP, Miquelini M, Doma K, Libardi CA. Muscle damage responses to resistance exercise performed with high-load versus low-load associated with partial blood flow restriction in young women. Eur J Sport Sci. 2019:1-10.

74. Braganca RD, Ravetti CG, Barreto L, et al. Use of handgrip dynamometry for diagnosis and prognosis assessment of intensive care unit acquired weakness: a prospective study. Heart Lung. 2019;48(6):532-7. https://doi. org/10.1016/j.hrtlng.2019.07.001.

75. Hermans G, Clerckx B, Vanhullebusch T, Segers J, Vanpee G, Robbeets C, et al. Interobserver agreement of Medical Research Council sum-score and handgrip strength in the intensive care unit. Muscle Nerve. 2012;45(1):1825. https://doi.org/10.1002/mus.22219.

76. Parry SM, Berney S, Granger CL, Dunlop DL, Murphy L, el-Ansary D, et al. A new two-tier strength assessment approach to the diagnosis of weakness in intensive care: an observational study. Crit Care. 2015;19(1):52. https://doi. org/10.1186/s13054-015-0780-5
77. Denehy L, de Morton NA, Skinner EH, Edbrooke L, Haines K, Warrillow S, et al. A physical function test for use in the intensive care unit: validity, responsiveness, and predictive utility of the physical function ICU test (scored). Phys Ther. 2013:93(12):1636-45. https://doi.org/10.2522/ptj.20120310.

78. Silva V, Araujo JAN, Cipriano G Jr, et al. Brazilian version of the Functional Status Score for the ICU: translation and cross-cultural adaptation. Rev Bras Ter Intensiva. 2017;29(1):34-8. https://doi.org/10.5935/0103-507X.20170006.

79. Paixao CM Jr, Reichenheim ME. A review of functional status evaluation instruments in the elderly. Cad Saude Publica. 2005;21(1):7-19.

80. Silveira L, Silva JMD, Soler JMP, Sun CYL, Tanaka C, Fu C. Assessing functional status after intensive care unit stay: the Barthel Index and the Katz Index. Int J Qual Health Care. 2018;30(4):265-70. https://doi.org/10.1 093/intahc/mzx203.

81. Schweickert WD, Pohlman MC, Pohlman AS, Nigos C, Pawlik AJ, Esbrook CL, et al. Early physical and occupational therapy in mechanically ventilated, critically ill patients: a randomised controlled trial. Lancet. 2009;373(9678): 1874-82. https://doi.org/10.1016/S0140-6736(09)60658-9.

82. Chiang LL, Wang LY, Wu CP, Wu HD, Wu YT. Effects of physical training on functional status in patients with prolonged mechanical ventilation. Phys Ther. 2006;86(9):1271-81. https://doi.org/10.2522/ptj.20050036.

83. van der Schaaf M, Dettling DS, Beelen A, Lucas C, Dongelmans DA, Nollet F. Poor functional status immediately after discharge from an intensive care unit. Disabil Rehabil. 2008;30(23):1812-8. https://doi.org/10.1080/096382 80701673559

84. Delle Karth G, Meyer B, Bauer S, Nikfardjam M, Heinz G. Outcome and functional capacity after prolonged intensive care unit stay. Wien Klin Wochenschr. 2006;118(13-14):390-6. https://doi.org/10.1007/s00508-006-0616-z.

85. Montuclard L, Garrouste-Orgeas M, Timsit JF, Misset B, De Jonghe B, Carlet J. Outcome, functional autonomy, and quality of life of elderly patients with a long-term intensive care unit stay. Crit Care Med. 2000;28(10):3389-95. https://doi.org/10.1097/00003246-200010000-00002.

86. Ware JE Jr, Sherbourne CD. The MOS 36-item short-form health survey (SF36). I. Conceptual framework and item selection. Med Care. 1992;30(6):47383. https://doi.org/10.1097/00005650-199206000-00002.

87. Davidson TA, Caldwell ES, Curtis JR, Hudson LD, Steinberg KP. Reduced quality of life in survivors of acute respiratory distress syndrome compared with critically ill control patients. JAMA. 1999;281(4):354-60. https://doi.org/1 0.1001/jama.281.4.354

88. Gerth AMJ, Hatch RA, Young JD, Watkinson PJ. Changes in health-related quality of life after discharge from an intensive care unit: a systematic review. Anaesthesia. 2019;74(1):100-8. https://doi.org/10.1111/anae.14444.

89. Cohen J. Statistical power analysis for the behavioral sciences. 2nd ed. Hillsdale, NJ: Lawrence Erlbaum; 1988.

90. Granger $\mathrm{CL}$, Holland AE, Gordon IR, Denehy L. Minimal important difference of the 6-minute walk distance in lung cancer. Chron Respir Dis. 2015;12(2): 146-54. https://doi.org/10.1177/1479972315575715.

91. Paris MT, Mourtzakis M, Day A, Leung R, Watharkar S, Kozar R, et al. Validation of Bedside Ultrasound of Muscle Layer Thickness of the Quadriceps in the Critically III Patient (VALIDUM Study). JPEN J Parenter Enteral Nutr. 2017;41(2):171-80. https://doi.org/10.1177/0148607116637852.

92. Weinel LM, Summers MJ, Chapple LA. Ultrasonography to measure quadriceps muscle in critically ill patients: a literature review of reported methodologies. Anaesth Intensive Care. 2019;47(5):423-34. https://doi.org/1 $0.1177 / 0310057 \times 19875152$.

93. Parry SM, El-Ansary D, Cartwright MS, et al. Ultrasonography in the intensive care setting can be used to detect changes in the quality and quantity of muscle and is related to muscle strength and function. J Crit Care. 2015; 30(5):1151 e1159-14.

94. Ferraz MB, Oliveira LM, Araujo PM, Atra E, Tugwell P. Crosscultural reliability of the physical ability dimension of the health assessment questionnaire. $J$ Rheumatol. 1990;17(6):813-7.

95. Kelmenson DA, Held N, Allen RR, Quan D, Burnham EL, Clark BJ, et al. Outcomes of ICU patients with a discharge diagnosis of critical illness polyneuromyopathy: a propensity-matched analysis. Crit Care Med. 2017; 45(12):2055-60. https://doi.org/10.1097/CCM.0000000000002763.

\section{Publisher's Note}

Springer Nature remains neutral with regard to jurisdictional claims in published maps and institutional affiliations. 